\title{
A VALORIZAÇÃO DO POTENCIAL CULTURAL MATERIAL LOCAL: ESTUDO DA CULTURA ÍTALO-BRASILEIRA NA QUARTA COLÔNIA/RS
}

\author{
Maria da Graça Portela LISBOA ${ }^{\mathrm{i}}$
}

\section{RESUMO}

O presente estudo foi elaborado a partir de ampla pesquisa de campo no município de Silveira Martins, Quarta Colônia/RS onde foram coletados dados acerca do trabalho artesanal feito com a palha de milho ensinado pelos primeiros imigrantes italianos e sua preservação na cultura material com seus descendentes. Segue uma análise sobre os resultados encontrados, que considera sua importância na relação estabelecida entre a cultura local e o global, contextualizada no âmbito dos processos de comunicação para o desenvolvimento local.

PALAVRAS-CHAVE: cultura regional; comunicação; produção artesanal.

\section{RESUMEN}

El presente estudio se elaboró a partir de la investigación de campo en la ciudad de Silveira Martins, Quarta Colônia / RS, donde se recogieron datos sobre el trabajo realizado con maíz hechas a mano rastrojo enseñado por los primeros inmigrantes italianos y su conservación en la cultura material con sus descendientes. Sigue un análisis de los resultados, teniendo en cuenta su importancia en la relación establecida entre la cultura local y global, contextualizada en los procesos de comunicación para el desarrollo local.

PALABRAS CLAVE: cultura regional; comunicación, producción artesanal

\begin{abstract}
The present study was drawn from extensive field research in the town of Silveira Martins, Quarta Colônia / RS where data were collected about the work done with handmade corn stover taught by the early Italian immigrants and their preservation in material culture with their descendants. Follows an analysis of the results, considering its importance in the relationship established between the local and global culture, contextualized within the communication processes for local development.
\end{abstract}

KEY WORDS: regional culture, communication, craft production

\section{Introdução}

A cultura material na $4^{\text {a }}$ Colônia de Imigração Italiana em Silveira Martins - RS tem como um de seus materiais mais expressivos a palha de milho, utilizada para confeccionar diversos produtos artesanais. O objetivo deste trabalho é o desenvolver soluções para aplicação da técnica artesanal em palha de milho em produtos industriais como forma de valorizar o potencial artesanal da Quarta Colônia de Imigração Italiana. Trata-se de resgatar a cultura material (palha de milho) utilizada pelos imigrantes 
italianos, inserindo a cultura material na linguagem da comunicação e do design a partir de um produto que considere aspectos ecológicos, econômicos, estéticos e funcionais, viabilizando sua industrialização através de projeto de produtos.

Cabe ressaltar que as técnicas artesanais trazidas pelos imigrantes italianos para suprir suas necessidades devem ser estudadas pela ótica da comunicação e da cultura e podem ser aproveitadas pelo design, envolvendo as emoções sociais e psicológicas do indivíduo, com conseqüência na ergonomia, na estética, nas técnicas, na ecologia, além dos aspectos simbólicos e metodológicos do produto. Este trabalho justifica-se pela oportunidade de resgate de cultural, a partir de uma técnica antiga - o trançado da palha de milho - na confecção de um produto industrial, aliando assim a técnica artesanal com a produção industrial. Objetiva-se, assim, criar um produto estético e funcional, cujo significado está além da simples utilização do mesmo, alcançado a identidade cultural dos imigrantes e de seus descendentes. Esta utilização do trançado de palha de milho ainda é realizada pelos descendentes de italianos na $4^{\mathrm{a}}$ Colônia de Imigração, no município de Silveira Martins/RS, sendo fonte de renda através do artesanato. Desta forma, pretende-se buscar a fabricação de um produto com identidade, localizando-o o dentro de uma cultura. Desse modo, a referida pesquisa busca raízes na cultura colonial ítalo no RS, sua contribuição cultural e seu conjunto de significações em um elemento do artesanato - o trançado com palha de milho, para se desenvolver um novo produto com referência cultural.

\section{Identidade, cultura e tradição}

A expressão identidade, grosso modo, significa um conjunto de traços e características que identificam um grupo social, distinguindo-o dos demais grupos. As identidades se fazem existentes a partir dos atributos oferecidos na linguagem e no sistema simbólico em que são representadas, sendo assinaladas principalmente pela diferença. Os conteúdos que mais se enfatizam na produção artesanal com a palha do milho se constituem como diferença em relação à vida cotidiana/industrializada e à globalizada. Por isso mesmo, podem assumir força como traço de identidade regional.

Woodward (2000) diz que as identidades são fabricadas por meio da marcação da diferença. Essa marcação da diferença ocorre tanto por meio de sistemas simbólicos de representação quanto por meio de formas de exclusão social.

Para Oliven (2006, p. 34), as identidades são “(...) construções sociais formuladas a partir de diferentes reais ou inventadas que operam como sinais 
diacríticos, isto é, sinais que conferem uma marca de distinção". Assim, é possível entendermos a constante reconstrução da identidade, tendo em vista, principalmente, as trocas sociais que se configuram no meio. Por outras palavras, "a identidade (...) faz parte da complexidade do social. (...) Nenhum grupo, nenhum indivíduo está fechado $a$ priori em uma unidimensional”. (CUCHE, 1999, p. 192).

Se um dos pontos relevantes na identidade cultural é a diferença, é preciso considerar ainda que há uma complexidade social que se constitui e "(...) cada indivíduo integra, de maneira sintética, a pluralidade das referências identificatórias que estão ligadas à sua história. (...) Cada indivíduo tem consciência de ter uma identidade de forma variável, de acordo com as dimensões do grupo social ao qual ele faz referência em tal ou tal situação relacional”. (CUCHE, 1999, p. 194)

Para Hall (1996, p. 69), “As identidades culturais provem de alguma parte, têm histórias. Mas, como tudo o que é histórico, sofrem transformação constante”. Assim, para o autor, não é possível determinar a identidade cultural em si mesma e definitivamente.

Neste sentido, atentar para o trabalho realizado pelos descentes dos imigrantes italianos que vieram para o Estado auxilia no entendimento da constituição da nossa sociedade. Cabe dizer que essas "práticas culturais" (produção artesanal a partir da palha de milho) são propaladas em função das tradições, que são organizadas a partir da memória coletiva de cada sociedade. No Rio Grande do Sul, muitas delas foram passadas de geração para geração por meio da oralidade, devido ao baixo índice de alfabetizados no estado até meados do século XX. Hoje essas tradições servem para reforçar a coesão social, segundo Oliven (2006). Para Hobsbawm e Ranger (1997), o culto à tradição não se opõe à modernidade. Ele se reproduz nela e, graças a ela, se mantém.

O local/regional e o nacional/global fazem um caminho semelhante no processo de construção de uma identidade, pois é com base no todo que se busca a diferenciação, ou seja, a partir do que o outro não tem ou não lhe é tão característico. “(...) uma cultura nacional é um discurso - um modo de construir sentidos que influencia e organiza tantos nossas ações quanto a concepção que temos de nós mesmos.” (HALL, 1999, p.147).

\section{Imigração italiana no RS}


As considerações feitas neste trabalho nos conduzem a história da ocupação italiana no RS há 130 anos. Os imigrantes saíram de sua terra natal - a Itália, em busca de dias melhores, deixando para trás a pátria. Em 1870, segundo Zero Hora (14105/05), "a unificação aprofundara a ligação da Península no mercado mundial, depreciando o preço dos cereais e golpeando a produção manufatureira rural. A população expulsa do campo encontrava com dificuldade trabalho na indústria italiana atrasada". Quando a população desesperada, mas esperançosa, volta-se para a América.

Imbuídos de coragem e força para lutar, os italianos acreditavam no trabalho como forma geradora de riquezas. Instaram-se no RS entre 1875 a 1914, como pequenos proprietários. Desenvolveram a agricultura familiar de subsistência, enfrentando a mata nativa e as intempéries das dificuldades, que não eram poucas, quando praticamente tudo estava por fazer.

Para os historiadores, coloca-se a colonização como movimento civilizador, que fora vinculada pela diplomacia italiana, desde o seu processo inicial de imigração, pelas classes rurais italianas, após 1880. Era um período que se considerava o sul da América como região de terras virgens e férteis, habitadas por selvagens, mas, apontava para a possibilidade de os imigrantes desbravarem, produzirem e desenvolverem.

Desse modo, milhares de colonos atravessaram o Atlântico para ocupar os pequenos lotes no sul do Brasil. Assim, incentivavam-se os núcleos familiares policultores que suprissem a carência de alimentos em sociedade monoprodutora. Ao lado do poder público, a Igreja exerceu muita influência junto a esses imigrantes, pois a Igreja via no colono a materialização do cristão verdadeiro.

A sociedade que se organizava no novo mundo provida de religião e certeza no trabalho, modificou sobremaneira o cenário econômico e agrícola/industrial no RS. Muito se deve a força do trabalho e a disposição de vencer desses colonos, num processo de transformação profunda e rica de valores culturais, sociais que se manifesta nos fazeres, saberes regionais e seus valores, crenças, hábitos e costumes.

Desse modo, conquistaram a estabilidade econômica e promissora em importantes regiões do RS, como a Serra Gaúcha com seu importante Pólo Industrial do estado, onde se observa também, no seu potencial turístico, o forte comércio como o trabalho em artesanato.

A região da Quarta Colônia, onde foi realizada a pesquisa, é assim denominada, pela história, por se tratar da quarta "leva" de colonos que chegou nas terras do sul do Brasil. Compreende os municípios de Nova Palma, Vale Vêneto, Faxinal do Soturno, 
Arroio do Só, São João do Polêsine, Ivorá, Dona Francisca e Silveira Martins, onde se iniciam os trabalhos de campo desta pesquisa. Segundo o pesquisador da imigração italiana no RS, Sponchiado, "em 1882 (...) Silveira Martins tornou-se o $5^{\circ}$ distrito de Santa Maria da Boca do Monte (...) o destino histórico seria o mesmo. Lá e aqui o futuro era sonhado com a mesma grandeza e com a mesma ousadia" (p. 425).

Observou-se através dos estudos cristalizados pelos historiadores, que essa colônia, como as demais estabelecidas no RS, eram impulsionadas pelo sonho da propriedade e confiança na força do trabalho, que se constituiu num fator determinante nos rumos do processo de desenvolvimento, em que o binômio propriedade/trabalho se constitui num processo de construção contínua das colônias.

Observa-se, em Silveira Martins/RS, ainda uma economia baseada na agricultura, com lavouras de arroz, milho, trigo. Percebe-se, também, a estagnação no seu desenvolvimento, mas nem por isso ficam despercebidas as riquezas culturais, artesanais e sociais dos seus habitantes. Encontram-se colonos trabalhadores, alegres, receptivos, que mantêm as tradições da sua pátria de origem, o que é notório em todo o legado cultural através dos seus hábitos, gastronomia, dialeto, religiosidade, disposição e fazeres artesanais.

\section{Artesanato e produção industrial}

A necessidade de criar objetos utensílios próprios acompanha o homem desde o início de sua história numa evolução constante, para atender as suas necessidades de uso. Nessa busca, evolui na elaboração e nos materiais a serem utilizados.

Quando o homem deixou de ser nômade e se fixou num determinado lugar para morar e produzir (Período Neolítico), já houve a necessidade de organizar o seu ambiente/entorno. E, para isso, desenvolveu manualmente os seus pertences, impulsionando, assim, o progresso do meio artesanal de fabricação.

\footnotetext{
A nova forma de vida deu origem a um grande número de habilidades e invenções, muito antes do surgimento dos metais: a cerâmica, a tecelagem, a fiação, métodos básicos de construção arquitetônica (...) origem a profundas alterações na maneira do homem ver-se a si próprio e ao mundo. (JANSON e JANSON, 1996, p. 17)
}

Deste modo, tem-se no artesanato uma forma de produção que acompanhou o desfecho da civilização até a era industrializada, surgida na Inglaterra no século XVIIXVIII, chamada de Revolução Industrial. A Revolução Industrial trouxe a possibilidade 
da produção seriada, através da manufatura mecanizada, onde os produtos industrializados são bens de consumo e também de capital. Contrapondo, assim, com a produção artesanal que é única e produzida manualmente. Esse dualismo produção industrial x produção artesanal trouxe divisões de opiniões muito acentuadas e a Escola de Arts and Grafts (1860 - 1900), influenciada por Willian Morris e Walter Gropius (seguidores de Ruskin) mantém seu apoio à concepção artesanal do trabalho. Morris considerava a máquina o seu inimigo mortal e se hostilizava com os novos meios de produção. Definiam os princípios do design industrial ao reconhecer as possibilidades do objeto como portador de certas qualidades estéticas, as quais, segundo Morris, eram fruto das qualidades artesanais e não da máquina. Defendia Morris em Pevsner (1995, p. 28) “(...) o que realmente importa é o trabalho manual". Morris foi um fiel seguidor de Ruskin e, na tentativa de influir diretamente nas situações degradantes da sociedade, sugere oportunidades através das quais se realiza a transformação da mesma. Também, colocou em destaque o interesse social de que o produto industrial podia ser portador. E à medida que precisa reconhecer a existência da máquina, dá início a uma série de empreendimentos comerciais que vão divulgar a importância do design, como um princípio organizador da sua existência comercial.

Os estudos em Löbach (2001) apontam-nos para a importância do design na relação do homem com o seu ambiente. Assim, é necessário considerar o homem em sua dimensão total, envolvendo seus aspectos sociais, emocionais, psicológicos e culturais. Aí reside o argumento central de estudá-lo pelo viés da comunicação. Löbach (2001, p. 25) corrobora que o homem influi em seu ambiente e o modifica mediante sua atuação.

De modo que, o design, respaldado pela comunicação, volta-se para a qualidade, a estética, a inovação, a performance, ao custo, ao público, a cultura, a informação, a marca, ao benefício, a análise de viabilidades para o desenvolvimento de um novo produto, visando, desse modo, a um processo de transformação na sociedade. Nesse contexto, encontra-se o designer que, por ser o projetista do produto, é também um elemento componente de uma rede social mais ampla, que compreende a produção, a distribuição e o uso do objeto.

Por outro lado, sabe-se que cada sociedade tem a forma de produzir os seus produtos, uma tecnologia de acordo com o seu contexto natural e cultural e, sujeitos as leis ecológicas que regem o controle ambiental onde estão inseridas. Portanto, o contexto ecológico faz parte do resultado do trabalho que se destina ao uso do 
consumidor cumprindo, assim, sua função de utilidade. Compreende-se, aqui, o termo utilidade, abrangente num conceito clássico de funcionalidade.

Desde Bauhaus, L. Sullivan (1896), "a forma segue a função" está associado ao design, independente das contestações ao funcionalismo pela Sociedade Industrial Contemporânea. Essas discussões permeiam o desfecho dessa sociedade moderna industrializada e hoje nos remetem a um mundo globalizado, onde se vivencia a era da informação/informatização. Em Barichello (1999, p. 2), encontra-se que o final do século XX é marcado pelo triunfo do capitalismo, que hoje se expressa numa economia compactada, mundializada ou globalizada, auxiliada pelo marketing e a publicidade, o que para o referido autor, desencadeou-se um consumo em massa.

Entende-se por produção massificada a que descaracteriza a individualidade, pois prioriza o coletivo. Por outro lado, sabe-se da importância da economia entendida global a sua influencia no progresso e no entendimento entre os povos de diferentes nações.

De modo que, no processo de globalização, busca-se um referencial característico da cultura local - nesse estudo a ítalo, aliando-se à tecnologia e ao artesanato, num processo de desenvolvimento de produto voltado para o consumidor.

\section{Apontamentos conclusivos}

Através das análises, observações e visitas realizadas, constatou-se a importância do artesanato da cultura ítalo na região da Quarta Colônia/RS, mais especificamente em Silveira Martins. Muitas técnicas artesanais ainda estão em uso, como trançado da palha de milho, em uma produção reduzida a pequenos objetos e utilitários.

A lavoura mecanizada reduziu e muito a matéria prima (palha) e a necessidade de produzir seus próprios mobiliários foi substituída pela facilidade de adquirir produtos de forma industrializada, incentivados pelas facilidades proporcionados pela modernidade.

Observou-se a preocupação entre os detentores do conhecimento dessa técnica o temor de que haja menos interessados pelo trabalho. Acrescido do fato de os mais jovens estarem mais voltados para os meios de desenvolvimento que o avanço das tecnologias e as facilidades advindas daí.

Assim, dada a importância da cultura material produzida artesanalmente na preservação da cultura ítalo, frente ao processo de globalização, há necessidade de regionalizar os produtos, conferindo-lhe identidade. Neste sentido, sugere-se o 
desenvolvimento de um trabalho junto aos produtores artesanais da Região, com base em experiências comunicativo-midiáticas e o design, para valorização do potencial cultural material local.

\section{Referências}

BARICHELLO, Carlos Eduardo. Cultura material: o desenho da cadeira colonial italiana. Santa Maria: UFSM, 1999. Tese, Universidade Federal de Santa Maria.

COMPONENTS IMPORTAÇÃO E EXPORTAÇÃO. Folder promocional - rattan. São Bento do Sul, SC, 2005.

COSTA, Rovilio; BATTISTEL, Arlindo I. Assim vivem os italianos: religião, música, trabalho e lazer. Caxias do Sul: Universidade de Caxias, 1983.

JANSON, H. W. ; JANSON, Anthony E. Iniciação à história da arte. (Tradução de Jefferson Luiz Camargol). 2. ed. São Paulo: Martins Fontes, 1996.

LEMOS, Iara. Qui si parla italiano. Diário de Santa Maria, Santa Maria, 07 de maio de 2005 .

LÖBACH, Bernd. Design industrial: bases para a configuração dos produtos industriais. Rio de Janeiro: Ed. Edgard Blücher, 2001.

MAESTRI, Mário. Imigração Italiana: entre a história e o mito. Zero Hora, Porto Alegre, 14 de maio de 2005.

PEVSNER, Nikolaus. Os pioneiros do desenho moderno; de Willian Morris a Waçter Gropiuns. São Paulo: Martins Fontes, 1995.

PORCIÚNCULA, Bruna. Cenas da Itália. Diário de Santa Maria, Santa Maria, 07 de maio de 2005.

SECRETARIA DE TURISMO DE VILA FLORES. Guia turístico: conheça nossa cultura. Vila Flores, RS, 2005.

SPONCHIADO, Luiz. A anágrafe de Nova Palma e os inícios da Colônia Silveira Martins.

\section{Notas}

\footnotetext{
${ }^{\text {i }}$ Designer e Mestre. Professora Assistente do Curso de Design do Centro Universitário Franciscano Santa Maria RS, Membro do GP Comunicação, Identidades e Fronteira da UFSM, email: mglisboa@yahoo.com.br
} 